\title{
Association of Overt Diabetes Mellitus with the Non-CC but not the CC Genotype of Interleukin-28B in Hepatitis C Virus Infected Patients
}

\author{
Ashish Kumar*, Varun Gupta, Praveen Sharma, Naresh Bansal, Vikas Singla and Anil Arora \\ Institute of Liver, Gastroenterology, \& Panceatico-Biliary Sciences, Sir Ganga Ram Hospital, New Delhi, India
}

\begin{abstract}
Background: Interleukin-28B (IL-28B) polymorphism is an important predictor for hepatitis C virus (HCV) treatment response. Whether IL-28b genotypes also influence other nontreatment related clinical parameters is unclear. Methods: Patients with HCV-related chronic liver diseases who attended our department during 2012-2014 were retrospectively analyzed. The single nucleotide polymorphisms (SNPs) of rs12979860 (IL-28B) were correlated with various clinical parameters. We also compared these parameters in patients with and without overt diabetes to identify possible associations. Results: A total of 115 patients were included (median age 48 , range $15-76$ years; $70 \%$ males). Overall, $43 / 115$ $(37 \%)$ patients had chronic hepatitis, while the remaining $72 / 115$ (63\%) had cirrhosis. The most common IL-28B genotype was CC, which was found in $53 \%$ of patients $(61 / 115)$, while the remaining $47 \%$ were nonCC [CT $42 \%$ (48/115) and Tा 5\% (6/115)]. Clinical and laboratory parameters like $\mathrm{Hb}$, white blood cell (WBC), platelets, bilirubin, transaminases, and albumin were similar in the CC and nonCC genotypes. Overt diabetes mellitus was present in $22 \%(25 / 115)$ of patients. Patients with nonCC genotype had significantly higher prevalence of overt diabetes mellitus than patients with CC genotype $(31 \%[17 / 54]$ versus $13 \%[8 / 61] ; p<0.05)$. When parameters were compared in patients with and without overt diabetes mellitus, only IL-28B and age were significantly associated with overt diabetes mellitus $(p<0.05)$. Conclusion: In $\mathrm{HCV}$ patients, overt diabetes mellitus was more commonly associated with the nonCC genotype of IL-28B than the CC genotype. Carriers of the T-allele of SNP rs12979860 were
\end{abstract}

Keywords: Chronic hepatitis C; Diabetes mellitus; Cirrhosis; IL-28B; Chronic liver disease; Insulin resistance.

Abbreviations: ALT, alanine aminotransferase; AST, aspartate aminotransferase; $\mathrm{BMI}$, body mass index; $\mathrm{CBC}$, complete blood count; $\mathrm{CBG}$, corticosteroid binding globulin; DAAs, direct acting antivirals; dNTPs, deoxynucleotide triphosphates; ESRD, end-stage renal disease; GWAS, genome wide associated study; HBsAg, hepatitis B surface antigen; HBV, hepatitis B virus; HCC, hepatocellular carcinoma; $\mathrm{HCV}$, hepatitis $\mathrm{C}$ virus; HIV, human immunodeficiency virus; HOMA-IR, homeostasis model assessment of insulin resistance; IFNL3, Interferon-lambda 3; IL-28B, Interleukin-28B; OGTT, oral glucose tolerance test; $P C R$, polymerase chain reaction; RFLP, restriction fragment length polymorphism; SNPs, single nucleotide polymorphisms; SVR, sustained virological response; TLC, total leukocyte count. Received: 31 October 2015; Revised: 30 December 2015; Accepted: 05 January 2016

DOI: $10.14218 /$ JCTH.2016.00040.

*Correspondence to: Ashish Kumar, Institute of Liver, Gastroenterology, \& Panceatico-Biliary Sciences, Ganga Ram Institute for Postgraduate Medical Education \& Research (GRIPMER), Sir Ganga Ram Hospital, Rajinder Nagar, New Delhi, 110 060, India. Tel: +91-9312792573, Fax: +91-11-25861002, Email: ashishk10@yahoo.com more likely to have insulin resistance than CC homozygotes, and this finding may explain the higher prevalence of diabetes in non-CC genotypes. Thus, an IL-28B test may be useful in patients of HCV in order to determine their likelihood of developing diabetes mellitus.

(c) 2016 The Second Affiliated Hospital of Chongqing Medical University. Published by XIA \& HE Publishing Inc. All rights reserved.

\section{Introduction}

Interferon-lambda 3 (IFNL3), also termed interleukin (IL)$28 \mathrm{~B}$, is encoded by the innate immunity gene on chromosome 19 and is a member of the type III interferons. Genome-wide association studies (GWAS) and subsequent validation studies conducted by several groups around the world have reported that single nucleotide polymorphisms (SNPs) around this gene are strongly associated with both hepatitis $\mathrm{C}$ virus (HCV) spontaneous clearance and treatment-response to pegylated-interferon and ribavirin combination therapy. Like other type III interferons, such as IL-29 and IL-28A, IL-28B exhibits a strong antiviral function and induces interferon-stimulated genes. ${ }^{1,2}$ The SNP designated rs 12979860 is located 3 kilobases upstream of the IL-28B gene. ${ }^{3,4}$ The rs 12979860 locus can be occupied by either the nucleotide cytosine (C) or thymine (T). HCV infected people with $C$ at location rs12979860 in both alleles of the IL-28B gene (the IL-28B CC genotype) are more likely to have a favorable outcome than those born with $\mathrm{T}$ at this location in one (the CT genotype) or both of their alleles (the TT genotype).

Chronically HCV infected individuals often develop severe liver inflammation and fibrosis, leading to an increased risk of liver cirrhosis and hepatocellular carcinoma (HCC) if left untreated. The likelihood of developing cirrhosis and decompensation of liver disease is augmented in the presence of various risk factors, such as older age, male gender, diabetes mellitus, alcohol abuse, and co-infection with human immunodeficiency virus (HIV) or hepatitis B virus (HBV). Among these, diabetes is an important and an independent prognostic factor of major liver outcomes in patients with HCV. ${ }^{5}$ Moreover, if chronic hepatitis $C$ patients develop new onset diabetes mellitus, then the incidence of cirrhosis and decompensation has been shown to increase over time. ${ }^{6}$

The overall incidence of diabetes in patients with HCV is increasing. It is possible that HCV infection promotes insulin resistance, but the mechanisms are not fully understood. It 
was previously shown that viral eradication improved insulin sensitivity in patients with chronic hepatitis $C^{7}$ More recently, it was shown that IL-28B gene polymorphisms were associated with the development of type 2 diabetes, hyperlipidemia, and hepatic steatosis in hepatitis $C$ infected transplant recipients. ${ }^{8,9}$ Thus, a mechanistic association between IL-28B unfavorable genotypes and insulin resistance is possible; and if such a link is present, then IL-28B genotype information may improve the ability to counsel patients regarding their individualized risk of diabetes, diabetes-related complications, and increased risk of cirrhosis and decompensation. However, there is scarce data available in the literature on this important association. ${ }^{10}$

In the present study we aimed to determine the relationship between IL-28B rs12979860 C/T gene polymorphism with overt diabetes mellitus and other nontreatment related clinical parameters in HCV patients. Although other SNPs in the IL-28B gene were identified previously (such as rs8099917 and rs12980275), here, we refer to the IL-28B rs12979860 C/T gene polymorphism as IL-28B.

\section{Patients and methods}

\section{Study population}

In this retrospective analysis, patients with $\mathrm{HCV}$ related chronic liver disease attending Sir Ganga Ram Hospital, New Delhi, from 2012 to 2014 were analyzed. Patients were included in the study only if: (1) they were aged above 14 years; (2) they had confirmed antiHCV positivity or had detectable HCV RNA viral load; (3) they were negative for HIV and hepatitis B surface antigen (HBsAg); and (4) they had IL-28B rs12979860 gene polymorphism data. The ethics committee approved the study and informed consent was obtained from each patient prior to inclusion.

\section{Data collection and clinical evaluation}

Data from included patients were analyzed to obtain information on history, physical examination, complete blood count, fasting blood sugar, liver function test, renal function test, prothrombin time, international normalized ratio (INR), ultrasound abdomen, baseline HCV RNA by quantitative real-time polymerase chain reaction (PCR) assay (Cobas Taqmen 48, Roche, Basel, Switzerland), HCV genotype by real-time PCR assay, and upper gastrointestinal endoscopy, as indicated.

Patients were reviewed for comorbidities like diabetes mellitus, hypertension, chronic kidney disease, hypovitaminosis $D$, and hypothyroidism. Patients were also reviewed for risk factors of HCV acquisition, i.e., blood transfusion, surgery, needle stick injury, dental procedure, tattooing, acupuncture, unprotected intercourse with multiple sexual partners, and intravenous drug abuse. Patients with significant alcohol intake were defined as those who regularly consumed $>40 \mathrm{~g}$ of alcohol per day for at least 10 years prior to presentation.

After complete evaluation of the HCV patients, they were categorized into one of two groups: chronic hepatitis and cirrhosis. Diagnosis of cirrhosis was made on the basis of clinical, biochemical, radiologic, endoscopic, or histologic findings. Severity of cirrhosis was graded based on the Child-Pugh classification.

\section{IL-28B polymorphism}

Genotyping for the IL-28B rs12979860 C/T in our patients was determined by restriction fragment length polymorphism (RFLP) from whole genomic DNA. The genomic DNA was isolated from whole blood using a commercial kit (Roche Diagnostics $\mathrm{GmbH}$, Mannheim, Germany) as per the manufacturer's instruction. The isolated DNA was electrophoresed on $1 \%$ agarose gels for quality check and quantified using nanodrop for purity. The PCR was carried out using the following primer pairs: 5'-GCGGAAGGAGCAGTTGCGCT-3' and 5'-GGGGCTTTGCTGGGGGAGTG-3'. Each reaction included $100-150 \mathrm{ng}$ genomic DNA as template in a total volume of $25 \mu \mathrm{L}$ having $1 \mathrm{X}$ PCR reaction buffer. Each forward and reverse primer was added to a final concentration $10 \mathrm{pmol} /$ reaction. Taq DNA polymerase (Fermentas, Thermo Fisher Scientific, Boston, MA, USA ), 2 U/reaction, was used for DNA amplification, with $125 \mu \mathrm{mol}$ each of deoxynucleotide triphosphates (dNTPs). The reaction mixture was subjected to PCR: initial denaturation at $94^{\circ} \mathrm{C}$ for $5 \mathrm{~m}, 35$ cycles, including denaturation at $94^{\circ} \mathrm{C}$ for $30 \mathrm{~s}$, annealing at $65^{\circ} \mathrm{C}$ for $30 \mathrm{~s}$, and elongation at $72^{\circ} \mathrm{C}$ for $30 \mathrm{~s}$, and final elongation at $72^{\circ} \mathrm{C}$ for $5 \mathrm{~m}$ using Veriti 96-well thermal cycler (Applied Biosystems, Carlsbad, CA, USA). For RFLP analysis, $10 \mu \mathrm{L}$ of amplified product were digested with $5 \mathrm{U}$ of Bst $\mathrm{U} 1$ restriction endonuclease (New England Biolabs, Ipswich, MA, USA) in a total volume of $20 \mu \mathrm{L}$ at $60^{\circ} \mathrm{C}$ for overnight. The restriction digested DNA was electrophoresed on 3\% agarose gel along with a $100 \mathrm{bp}$ ladder and visualized by a gel doc unit (Biorad, Hercules, CA, USA). The digested fragment was $196 \mathrm{bp}$ and $45 \mathrm{bp}$ for CC genotype; $241 \mathrm{bp}, 196 \mathrm{bp}$, and $45 \mathrm{bp}$ for CT; and $241 \mathrm{bp}$ for TT genotype.

\section{Outcomes}

The outcome of interest was overt diabetes mellitus. Diabetes mellitus was defined based on the patient's self-reported history of diabetes or use of diabetes-related medications, fasting glucose level (> $126 \mathrm{mg} / \mathrm{dL}$ ), or non-fasting glucose (> $200 \mathrm{mg} / \mathrm{dL}$ ).

Our predictor variable of interest was IL-28B rs12979860 genotype. We categorized this variable into two groups: IL-28B CC genotype (i.e., homozygous for allele CC) and IL-28b nonCC genotype (i.e., heterozygous CT or homozygous TT). The presence or absence of diabetes mellitus in HCV patients was compared in these IL-28B groups. Other parameters, both parameteric and nonparametric, for the risk of diabetes were also compared. We also examined whether IL-28B genotypes influenced other nontreatment related clinical parameters, like body mass index (BMI), liver enzymes, bilirubin, albumin, hemoglobin, total leukocyte count, platelets, baseline HCV RNA, end stage renal disease, significant alcohol intake, and stage of liver disease (chronic hepatitis or cirrhosis).

\section{Statistical analysis}

Continuous data are represented as median (range) and were compared using the Mann-Whitney $U$ test. Categorical data are expressed as number and percentage and were compared using the Fisher's exact test or Chi square test. If multiple factors were found to predict significantly diabetes mellitus on univariate analysis, they were entered into multivariate analysis by binary logistic regression to determine 
independent factors predicting diabetes. Statistical analyses were performed using SPSS 17.0 (Chicago, IL, USA), where $p<0.05$ was considered statistically significant.

Results

\section{Patients}

A total of $799 \mathrm{HCV}$ patients who were admitted during the study period were enrolled. After applying inclusion criteria, 115 patients were included in the study, and their data were analyzed.

\section{Baseline characteristics}

Baseline characteristics of study patients are shown in Table 1 . The median age was 48 years (range 15-76), and $70 \%$ of our study population was male (80/115). The median BMI of the patients was $24.0 \mathrm{~kg} / \mathrm{m}^{2}$ (range 15.0 $\left.38.5 \mathrm{~kg} / \mathrm{m}^{2}\right)$. Twenty-three percent $(27 / 115)$ of patients gave history of alcohol abuse in cirrhogenic doses. End

Table 1. Baseline characteristics of patients included in the study

\begin{tabular}{|c|c|}
\hline Parameter & Value \\
\hline Age (years) & $48(15-76)$ \\
\hline \multicolumn{2}{|l|}{ Gender, \% (n/n) } \\
\hline Males & $70 \%(80 / 115)$ \\
\hline Females & $30 \%(35 / 115)$ \\
\hline $\mathrm{BMI}, \mathbf{k g} / \mathbf{m}^{2}$ & $24(15-38)$ \\
\hline \multicolumn{2}{|l|}{ Comorbidities, \% (n/n) } \\
\hline Diabetes & $22 \%(25 / 115)$ \\
\hline Alcoholics & $24 \%(27 / 115)$ \\
\hline ESRD & $9 \%(10 / 115)$ \\
\hline \multicolumn{2}{|l|}{ Liver status $\%(n / n)$} \\
\hline Chronic hepatitis & $37 \%(43 / 115)$ \\
\hline Cirrhosis & $63 \%(72 / 115)$ \\
\hline \multicolumn{2}{|l|}{ HCV genotype, \% (n/n) } \\
\hline Genotype 3 & $67 \%(77 / 115)$ \\
\hline Genotype 1 & $16 \%(18 / 115)$ \\
\hline Genotype 4 & $8 \%(9 / 115)$ \\
\hline Genotype 2 & $1 \%(1 / 115)$ \\
\hline Genotype $3+4$ & $1 \%(1 / 115)$ \\
\hline Genotype $1+3$ & $8 \%(9 / 115)$ \\
\hline \multicolumn{2}{|l|}{ HCV RNA, \% (n/n) } \\
\hline High $\left(>4 \times 10^{5} \mathrm{IU} / \mathrm{mL}\right)$ & $45 \%(52 / 115)$ \\
\hline Low (615 to $\left.4 \times 10^{5} \mathrm{IU} / \mathrm{mL}\right)$ & $50 \%(58 / 115)$ \\
\hline $\begin{array}{l}\text { Undetectable or very low } \\
(<615 \mathrm{IU} / \mathrm{mL})\end{array}$ & $4 \%(4 / 115)$ \\
\hline \multicolumn{2}{|l|}{ IL-28b, \% (n/n) } \\
\hline $\mathrm{C} / \mathrm{C}$ & $53 \%(61 / 115)$ \\
\hline $\mathbf{C} / \mathbf{T}$ & $42 \%(48 / 115)$ \\
\hline $\mathbf{T} / \mathbf{T}$ & $5 \%(6 / 115)$ \\
\hline
\end{tabular}

ESRD, end-stage renal disease; $\mathrm{HCV}$, hepatitis $\mathrm{C}$ virus stage renal disease was present in $9 \%(10 / 115)$ of patients, cirrhosis was present in $63 \%(72 / 115)$ of patients, and chronic hepatitis was present in $37 \%(43 / 115)$ of patients. Liver biopsy was available in 31 patients; and in the remaining patients, the diagnosis of cirrhosis was made based on clinical, biochemical, radiologic, and/or endoscopic criteria. For HCV, genotype 3 was the most common genotype (67\%), followed by genotype 1 (16\%). The SNP for IL-28B rs 12979860 was the CC type in $53 \%(61 / 115)$ of patients, and the nonCC genotype was present in the remaining $47 \%$ of patients (CT in $42 \%$ and $T \mathrm{~T}$ in $5 \%$ ). Overt diabetes mellitus was present in $22 \%$ (25/115) of patients.

\section{Association between IL-28B rs12979860 and various nontreatment related variables}

The associations between IL-28B CC genotype and nonCC genotype with various parameters are shown in Table 2. Overall, $13 \%$ of patients with the CC genotype (favorable for sustained virological response (SVR)) had diabetes mellitus compared to $32 \%$ of nonCC genotype patients $(p<0.001)$ (Figure 1$)$. There were no differences for other variables between the CC and non-CC genotype groups.

Comparison of parameters between patients with and without overt diabetes mellitus

There were no significant differences between patients with overt diabetes and those without when comparing sex, BMI, chronic alcohol use, status of liver disease, complete blood count (CBC), and HCV genotype (Table 3 ). The incidence of overt diabetes mellitus was significantly less in the IL-28B CC genotype group than the nonCC genotype group $(p=0.023)$. The median age of patients with diabetes was significantly more than patients without overt diabetes $(p=0.001)$.

\section{Discussion}

The rs 12979860 SNP on the IL-28B gene was first identified in 2009 by Ge et al. ${ }^{3}$ by GWAS. This SNP was the strongest host genetic predictor of sustained virological response (SVR) in hepatitis $C$ patients. Over the last 5-6 years, a multitude of studies have been done on this IL-28B SNP and its role in the prediction of treatment response. Another SNP, rs8099917 on IL-28B, was also studied and compared with rs12979860 for its usefulness in predicting SVR in HCV. ${ }^{11,12,13}$ Subsequently, many other SNPs have been reported in HCV infection, ${ }^{14,15}$ but rs12979860 remains the most widely studied.

Although initially the IL-28B SNPs were used to predict treatment response to interferon and ribavirin in HCV patients, it is possible that these SNPs may influence other nontreatment related parameters as well. The role of IL-28B in the spontaneous clearance of virus in acute HCV and HCV recurrence in post-transplant patients is well documented. People who harbor the IL-28B CC genotype are three times more likely to spontaneously clear the virus than those with the CT or TT genotype. ${ }^{14}$ Similarly, liver transplant recipients with the IL-28B TT genotype exhibit more severe histologic recurrence of HCV infection. ${ }^{16,17}$ Lipid metabolism in HCV infected patients may also be influenced by the IL-28B genotype. As shown by Li et al., patients who carry the favorable CC allele had significantly higher levels of total cholesterol, apo-lipoprotein B, and low-density lipoprotein (LDL) cholesterol than those carrying the Tallele. ${ }^{18}$ 
Kumar A. et al: IL-28B and diabetes mellitus in HCV

Table 2. Comparison of IL-28B rs12979860 gene polymorphism and various nontreatment related characteristics

\begin{tabular}{|c|c|c|c|}
\hline Parameter & IL-28B CC genotype $(n=61)$ & IL-28B non-CC genotype $(n=54)$ & $\boldsymbol{p}$ value \\
\hline Age (years) & $48(15-76)$ & $48(23-75)$ & 0.937 \\
\hline Gender, \% (n/n) & & & 0.549 \\
\hline Males & $72 \%(44 / 61)$ & $67 \%(36 / 54)$ & \\
\hline Females & $28 \%(17 / 61)$ & $33 \%(18 / 54)$ & \\
\hline BMI, $\mathbf{k g} / \mathrm{m}^{2}$ & $23(15-38)$ & $24(17-39)$ & 0.534 \\
\hline Hemoglobin (g/dl) & $12(5-16)$ & $12(8-17)$ & 0.797 \\
\hline $\operatorname{TLC}\left(\times 10^{3} /\right.$ cumm $)$ & $6.1(6.3-14)$ & $5.9(4.7-16.3)$ & 0.771 \\
\hline Platelets ( $\times 10^{3} /$ cumm $)$ & $149(33-360)$ & $125(30-364)$ & 0.101 \\
\hline Bilirubin (g/dl) & $1.0(0.4-7.2)$ & $1.1(0.3-20.5)$ & 0.836 \\
\hline AST (IU/L) & $71(17-293)$ & $82(10-390)$ & 0.842 \\
\hline ALT (IU/L) & $59(14-392)$ & $88(12-393)$ & 0.278 \\
\hline Albumin (g/dI) & $3.8(2.2-5.0)$ & $3.5(1.9-5.0)$ & 0.159 \\
\hline HCV RNA, \% (n/n) High & & & 0.504 \\
\hline$\left(>4 \times 10^{5} \mathrm{IU} / \mathrm{mL}\right)$ Low & $48 \%(29 / 61)$ & $43 \%(23 / 54)$ & \\
\hline (615 to $\left.4 \times 10^{5} \mathrm{IU} / \mathrm{mL}\right)$ & $46 \%(28 / 61)$ & $56 \%(30 / 54)$ & \\
\hline Undetectable or very low ( $<615 \mathrm{IU} / \mathrm{mL})$ & $5 \%(3 / 61)$ & $2 \%(1 / 54)$ & \\
\hline Liver status \% $(n / n)$ & & & 0.443 \\
\hline Chronic hepatitis & $41 \%(25 / 61)$ & $33 \%(18 / 54)$ & \\
\hline Cirrhosis & $59 \%(36 / 61)$ & $67 \%(36 / 54)$ & \\
\hline \multicolumn{4}{|l|}{ Comorbidities \% (n/n) } \\
\hline Overt diabetes & $13 \%(8 / 61)$ & $32 \%(17 / 54)$ & 0.023 \\
\hline Alcoholics & $31 \%(18 / 61)$ & $15 \%(9 / 54)$ & 0.126 \\
\hline ESRD & $5 \%(3 / 61)$ & $13 \%(7 / 54)$ & 0.186 \\
\hline
\end{tabular}

ALT, alanine aminotransferase; AST, aspartate aminotransferase; BMI, body mass index; ESRD, end-stage renal disease; HCV, hepatitis C virus; TLC, total leukocyte count

The association between chronic hepatitis $C$ infection and increased incidence of diabetes mellitus has been observed in comparison to other causes of liver disease. ${ }^{19}$ In those patients with both hepatitis $C$ and diabetes, there is rapid

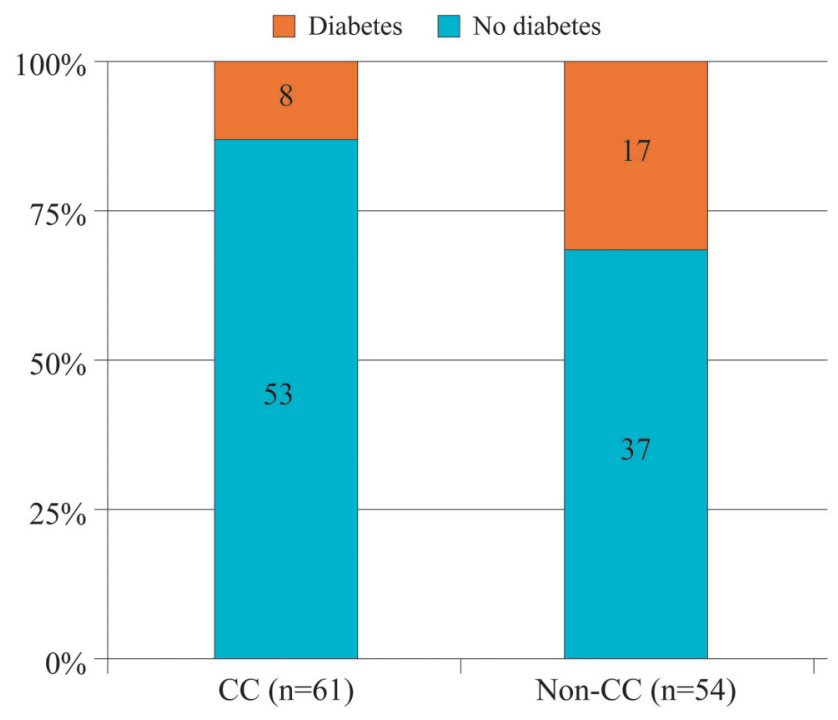

Fig. 1. Distribution of overt diabetes in IL-28B CC and nonCC genotypes. progression of fibrosis, early decompensation, and even an increase in the incidence of HCC. 5,6 The mechanisms underlying HCV related increases in insulin resistance and diabetes mellitus are not well understood. Studies have shown that $\mathrm{HCV}$ proteins may directly induce insulin resistance by impairing the insulin signaling pathway through several possible effectors, such as suppressor of cytokine signaling (SOC) and mammalian target of rapamycin. ${ }^{20,21}$

In our study, $22 \%$ of $\mathrm{HCV}$ patients had overt diabetes mellitus. When comparing IL-28B CC genotype and nonCC genotype in relation to different variables, we found that the frequency of overt diabetes mellitus was significantly different between these groups. We observed that patients with the nonCC genotype had a statistically higher frequency of overt diabetes mellitus than those with the CC genotype $(p<0.001)$. The median age of overt diabetics was also significantly higher than patients without overt diabetes. We also compared variables between patients with and without diabetes. There were no differences in BMI, status of liver disease, alcohol, and genotype between diabetic and non-diabetic patients, but there was a different in IL-28B genotype.

Our results are similar to those of Stattermayer et al., ${ }^{10}$ who in 2012 published that the IL-28B SNP rs12979860 nonCC genotype was an independent risk factor for insulin resistance. Compared to $\mathrm{CC}$ homozygotes, T allele carriers had a higher frequency of insulin resistance irrespective of the degree of fibrosis or steatosis. In another recent study 
Kumar A. et al: IL-28B and diabetes mellitus in HCV

Table 3. Comparison of parameters between patients with and without overt diabetes mellitus

\begin{tabular}{|c|c|c|c|}
\hline Parameter & With overt diabetes $(n=25)$ & Without overt diabetes $(n=90)$ & $\boldsymbol{p}$ value \\
\hline Age (years) & $57(39-76)$ & $46(15-75)$ & 0.001 \\
\hline Gender, \% (n/n) & & & 1.000 \\
\hline Males & $72 \%(18 / 25)$ & $69 \%(62 / 90)$ & \\
\hline Females & $28 \%(7 / 25)$ & $31 \%(28 / 90)$ & \\
\hline BMI, $\mathbf{k g} / \mathbf{m}^{2}$ & $23(17-37)$ & $24(15-38)$ & 0.551 \\
\hline Hemoglobin (g/dl) & $11.7(5.2-16.1)$ & $12.0(5.5-16.7)$ & 0.667 \\
\hline $\operatorname{TLC}\left(\times 10^{3} /\right.$ cumm $)$ & $6.0(2.5-13.2)$ & $6.0(4.7-16.3)$ & 0.712 \\
\hline Platelets ( $\times 10^{3} /$ cumm $)$ & $130(30-464)$ & $134(33-378)$ & 0.699 \\
\hline Bilirubin (g/dl) & $0.9(0.27-5.60)$ & $1.14(0.3-20.5)$ & 0.131 \\
\hline AST (IU/L) & $68(17-259)$ & $76(10-390)$ & 0.235 \\
\hline ALT (IU/L) & $69(14-199)$ & $76(12-393)$ & 0.737 \\
\hline Albumin (g/dl) & $3.8(2.4-4.4)$ & $3.7(1.9-5.0)$ & 0.860 \\
\hline Liver status, \% (n/n) & & & 0.161 \\
\hline Chronic hepatitis & $24 \%(06 / 25)$ & $41 \%(37 / 90)$ & \\
\hline Cirrhosis & $76 \%(19 / 25)$ & $59 \%(53 / 90)$ & \\
\hline Chronic alcohol, \%(n/n) & & & 0.597 \\
\hline Yes & $28 \%(07 / 25)$ & $22 \%(20 / 90)$ & \\
\hline No & $72 \%(18 / 25)$ & $78 \%(70 / 90)$ & \\
\hline IL-28B genotype & & & 0.023 \\
\hline CC & $32 \%(08 / 25)$ & $59 \%(53 / 90)$ & \\
\hline Non-CC & $68 \%(17 / 25)$ & $41 \%(37 / 90)$ & \\
\hline HCV genotype & & & 0.789 \\
\hline Genotype 1 and 4 & $27 \%(06 / 22)$ & $25 \%(21 / 83)$ & \\
\hline Genotype 2 and 3 & $73 \%(16 / 22)$ & $75 \%(62 / 83)$ & \\
\hline
\end{tabular}

ALT, alanine aminotransferase; AST, aspartate aminotransferase; BMI, body mass index

by Kanwal et al. ${ }^{22}$ on SNP rs12980275 of IL-28B, the investigators found that favorable AA IL-28B alleles have a lower prevalence of diabetes and related complications compared with patients with unfavorable alleles.

The specific mechanism by which IL-28B SNP genetic variations cause insulin resistance and diabetes are poorly understood. It has been suggested that unfavorable genotypes ( $T$ or $\mathrm{CT}$ ) may manifest higher interferon gene intensity. Interferon further suppresses insulin signaling via expression of SOCS-1 and SOCS $-3,{ }^{23}$ which cause insulin resistance through inhibition of tyrosine phosphorylation of insulin receptor substrate proteins by discrete mechanisms. ${ }^{24}$ Thus, a mechanistic link between IL-28B unfavorable genotypes ( $C T$ and $T T$ ) and insulin resistance can be postulated. But the impact of the IL-28B genotype on insulin resistance may be even more complex. Studies have found a strong relationship between corticosteroid binding globulin (CBG) peptides and the IL-28B genotype. CC carriers had lower CBG than T allele carriers. These observations suggest that the biological consequences of IL-28B may be unrelated to its effects on response to interferon-based therapy regulating metabolic pathways. ${ }^{10,25}$

There are, however, some limitations to our study. First, ours was a retrospective analysis, and we did not have adequate data to determine exactly whether diabetes was pre-existing or occurred after patients acquired HCV infection, as most patients with diabetes and HCV remain undiagnosed for years before they are diagnosed. Second, we did not have data of serum lipid levels, which may be influenced by IL-28B status. Third, homeostasis model assessment of insulin resistance (HOMA-IR), which is an important measure of insulin resistance, was not measured in our patients. However, we believe that our findings are still relevant, as development of diabetes mellitus is the most important reflection of ongoing insulin resistance. Fourth, a subset of subclinical diabetes mellitus may have gone undetected since we did not perform an oral glucose tolerance test (OGTT). It is currently known that almost $30 \%$ of patients with chronic liver disease without overt diabetes may test positive for diabetes on OGTT. ${ }^{26}$ Hence, we have labeled patients with diabetes in this study as having 'overt' diabetes. Fifth, since this is a retrospective study and we did not have exact records of time of onset of diabetes mellitus in relation to time of onset of liver injury, we were not able to classify diabetes as hereditary or hepatogenous.

To date, data are scarce in the literature on this important association between IL-28B and diabetes mellitus; further, large scale prospective studies are needed to validate our preliminary observations. IL-28B genotype information may improve the ability to counsel patients regarding their 
individualized risk of diabetes and diabetes-related complications and increased risk of cirrhosis and decompensation.

In conclusion, we found in HCV patients that the IL-28B SNP rs12979860 nonCC genotype was associated with a higher risk of overt diabetes mellitus. This association indicates that new genetic pathways may contribute to the occurrence of diabetes in HCV patients. Testing for IL-28B genotype was used clinically to predict treatment response with pegylated-interferon and ribavirin, but with the availability of new direct acting antivirals (DAAs), the utility of IL-28B had markedly diminished. However, given its role in predicting risk of diabetes in HCV patients, IL-28B genotype testing may be useful in patients with HCV.

\section{Conflict of interest}

None

\section{Author contributions}

Study design ( $A K, A A)$, recruitment of patients (VG), analysis and interpretation of data (AK, VG), manuscript writing (VG), critical revision (PS, NB, VS, AA), statistical analysis (AK), administration, technical or material support (AA).

\section{References}

[1] Donnelly RP, Kotenko SV. Interferon-lambda: a new addition to an old family. J Interferon Cytokine Res 2010;30:555-564. doi: 10.1089/jir.2010.0078.

[2] Li M, Liu X, Zhou Y, Su SB. Interferon-lambdas: the modulators of antivirus, antitumor, and immune responses. J Leukoc Biol 2009;86:23-32. doi: 10. $1189 / \mathrm{jlb} .1208761$.

[3] Ge D, Fellay J, Thompson AJ, Simon JS, Shianna KV, Urban TJ, et al. Genetic variation in IL28B predicts hepatitis C treatment-induced viral clearance. Nature 2009 17;461:399-401.

[4] Thompson AJ, Muir AJ, Sulkowski MS, Ge D, Fellay J, Shianna KV, et al. Interleukin-28B polymorphism improves viral kinetics and is the strongest pretreatment predictor of sustained virologic response in genotype 1 hepatitis C virus. Gastroenterology 2010;139:120-129. e18. doi: 10.1053/j. gastro.2010.04.013.

[5] Elkrief L, Chouinard P, Bendersky N, Hajage D, Larroque B, Babany G, et al. Diabetes mellitus is an independent prognostic factor for major liver-related outcomes in patients with cirrhosis and chronic hepatitis C. Hepatology 2014; 60:823-831. doi: 10.1002/hep.27228.

[6] Huang Y-W, Yang S-S, Fu S-C, Wang T-C, Hsu C-K, Chen D-S, et al. Increased risk of cirrhosis and its decompensation in chronic hepatitis $C$ patients with new-onset diabetes: a nationwide cohort study. Hepatology 2014;60:807814. doi: 10.1002/hep.27212.

[7] Romero-Gómez M, Fernández-Rodríguez CM, Andrade R], Diago M, Alonso S, Planas $R$, et al. Effect of sustained virological response to treatment on the incidence of abnormal glucose values in chronic hepatitis C. J Hepatol 2008; 48:721-727. doi: 10.1016/j.jhep.2007.11.022.

[8] Veldt BJ, Duarte-Rojo A, Thompson AJ, Watt KD, Heimbach JK, Tillmann HL, et al. Recipient IL28B polymorphism is an important independent predictor of posttransplant diabetes mellitus in liver transplant patients with chronic hepatitis C. Am J Transplant 2012;12:737-744. doi: 10.1111/j.1600-6143. 2011.03843.x.

[9] Tillmann HL, Patel K, Muir AJ, Guy CD, Li JH, Lao XQ, et al. Beneficial IL28B genotype associated with lower frequency of hepatic steatosis in patients with chronic hepatitis C. J Hepatol 2011;55:1195-1200. doi: 10.1016/j. jhep.2011.03.015.
[10] Stättermayer AF, Rutter K, Beinhardt S, Scherzer T-M, Stadlmayr A, Hofer H, et al. Association of the IL28B genotype with insulin resistance in patients with chronic hepatitis C. J Hepatol 2012;57:492-498. doi: 10.1016/j.jhep. 2012.04.036.

[11] Suppiah V, Moldovan M, Ahlenstiel G, Berg T, Weltman M, Abate ML, et al. IL28B is associated with response to chronic hepatitis $C$ interferon-alpha and ribavirin therapy. Nat Genet 2009;41:1100-1104. doi: 10.1038/ng.447.

[12] Tanaka Y, Nishida N, Sugiyama M, Kurosaki M, Matsuura K, Sakamoto N, et al. Genome-wide association of IL28B with response to pegylated interferonalpha and ribavirin therapy for chronic hepatitis C. Nat Genet 2009;41: 1105-1109. doi: 10.1038/ng.449.

[13] Li S, Hu P, Zhang Q-Q, Liu Y-H, Hu H-D, Zhang D-Z, et al. Single nucleotide polymorphisms of the IL28B and sustained virologic response of patients with chronic hepatitis C to PEG-interferon/ribavirin therapy: A meta-analysis: Meta-analysis of IL28B. Hepat Mon 2011;11:163-172.

[14] Prokunina-Olsson L, Muchmore B, Tang W, Pfeiffer RM, Park H, Dickensheets H, et al. A variant upstream of IFNL3 (IL28B) creating a new interferon gene IFNL4 is associated with impaired clearance of hepatitis C virus. Nat Genet 2013;45:164-171. doi: 10.1038/ng.2521.

[15] Chinnaswamy S, Chatterjee S, Boopathi R, Mukherjee S, Bhattacharjee S, Kundu TK. A single nucleotide polymorphism associated with hepatitis $C$ virus infections located in the distal region of the IL28B promoter influences NF-кB-mediated gene transcription. PLoS ONE 2013;8:e75495. doi: 10. 1371/journal.pone.0075495.

[16] Charlton MR, Thompson A, Veldt BJ, Watt K, Tillmann $\mathrm{H}$, Poterucha J], et al. Interleukin-28B polymorphisms are associated with histological recurrence and treatment response following liver transplantation in patients with hepatitis C virus infection. Hepatology 2011;53:317-324. doi: 10.1002/ hep. 24074.

[17] Graziadei IW, Zoller HM, Schloegl A, Nachbaur K, Pfeiffer K-P, Mark W, et al. Early viral load and recipient interleukin-28B rs12979860 genotype are predictors of the progression of hepatitis $\mathrm{C}$ after liver transplantation. Liver Transpl 2012;18:671-679. doi: 10.1002/lt.23402.

[18] Li JH, Lao XQ, Tillmann HL, Rowell J, Patel K, Thompson A, et al. Interferonlambda genotype and low serum low-density lipoprotein cholesterol levels in patients with chronic hepatitis C infection. Hepatology 2010;51:1904-1911. doi: 10.1002/hep.23592.

[19] White DL, Ratziu V, El-Serag HB. Hepatitis C infection and risk of diabetes: a systematic review and meta-analysis. J Hepatol 2008;49:831-844. doi: 10. 1016/j.jhep.2008.08.006.

[20] Pazienza V, Clément S, Pugnale P, Conzelman S, Foti M, Mangia A, et al. The hepatitis $C$ virus core protein of genotypes $3 a$ and $1 \mathrm{~b}$ downregulates insulin receptor substrate 1 through genotype-specific mechanisms. Hepatology 2007;45:1164-1171. doi: 10.1002/hep.21634.

[21] Douglas MW, George J. Molecular mechanisms of insulin resistance in chronic hepatitis C. World J Gastroenterol 2009;15:4356-4364. doi: 10.3748/wjg. 15.4356.

[22] Kanwal F, White DL, Jiao L, Tavakoli-Tabasi S, Sansgiry S, Ramsey DJ, et al. Genetic Variants in Interleukin-28B Are Associated with Diabetes and Diabetes-Related Complications in Patients with Chronic Hepatitis C Virus Infection. Dig Dis Sci 2015;60:2030-2037. doi: 10.1007/s10620-015-3545-8.

[23] Wada T, Hoshino M, Kimura Y, Ojima M, Nakano T, Koya D, et al. Both type I and II IFN induce insulin resistance by inducing different isoforms of SOCS expression in 3T3-L1 adipocytes. Am J Physiol Endocrinol Metab 2011;300: E1112-E1123. doi: 10.1152/ajpendo.00370.2010.

[24] Ueki K, Kondo T, Kahn CR. Suppressor of cytokine signaling 1 (SOCS-1) and SOCS-3 cause insulin resistance through inhibition of tyrosine phosphorylation of insulin receptor substrate proteins by discrete mechanisms. Mol Cell Biol 2004;24:5434-5446. doi: MCB.24.12.5434-5446.2004.

[25] Patel K, Lucas JE, Thompson JW, Dubois LG, Tillmann HL, Thompson AJ, et al. High predictive accuracy of an unbiased proteomic profile for sustained virologic response in chronic hepatitis C patients. Hepatology 2011;53: 1809-1818. doi: 10.1002/hep.24284.

[26] García-Compeán D, Jáquez-Quintana JO, Lavalle-González FJ, Reyes-Cabello E, González-González JA, Muñoz-Espinosa LE, et al. The prevalence and clinical characteristics of glucose metabolism disorders in patients with liver cirrhosis. A prospective study. Ann Hepatol 2012;11:240-248. 